\title{
Role of the cofilin 2 gene in regulating the myosin heavy chain genes in mouse myoblast $\mathrm{C} 2 \mathrm{C} 12$ cells
}

\author{
HONGYAN ZHU ${ }^{1}$, HUIXIN YANG $^{2}$, SONG ZHAO $^{3}$, JUNFENG ZHANG $^{1}$, \\ DAN LIU $^{1}$, YUMIN TIAN ${ }^{1}$, ZHIYI SHEN ${ }^{1}$ and YUHONG SU ${ }^{1}$ \\ ${ }^{1}$ College of Animal Science and Veterinary Medicine, Jinzhou Medical University, Jinzhou, Liaoning 121001; \\ ${ }^{2}$ College of Veterinary Medicine, Nanjing Agricultural University, Nanjing, Jiangsu 210000; \\ ${ }^{3}$ Central Laboratary, Jinzhou Medical University, Jinzhou, Liaoning 121001, P.R. China
}

Received January 21, 2016; Accepted November 15, 2017

DOI: $10.3892 /$ ijmm.2017.3272

\begin{abstract}
The cofilin 2 (CFL2) and myosin heavy chain $(M y H C)$ genes play a key role in muscle development and myofibrillar formation. The aim of the present study was to investigate the effect of CFL2 on genes involved in fiber formation and the mechanisms underlying this process. Undifferentiated and differentiated $\mathrm{C} 2 \mathrm{C} 12$ cells (UDT and DT, respectively) were transfected with CFL2 small interfering RNA (siRNA). CFL2 mRNA and protein levels were assessed using reverse transcription polymerase chain reaction (RT-PCR) and western blotting, respectively. $M y H C$ gene expression in UDT and signaling pathway-related factors were observed with quantitative PCR (RT-qPCR) and western blotting. Fluorescence microscopy was used to analyze the cytoskeletal effects of $C F L 2$. The mRNA and protein expressions of $C F L 2$, four $M y H C$ isoforms ( $M y H C-I$, $M y H C$-II,$M y H C$-IIb and $M y H C$-IIx), p38 mitogen-activated protein kinase, cAMP-response element-binding protein, AMP-activated protein kinase $\alpha 1$, and myocyte enhancer factor $2 \mathrm{C}$, were significantly decreased in UDT. However, extracellular signal-regulated kinase 2 expression was significantly increased. Slightly decreased CFL2 protein and mRNA expression was observed in DT C2C12 cells transfected with CFL2 siRNA. Fluorescence microscopy revealed a significant decrease of CFL2 in the cytoplasm, but not the nucleus, of UDT, compared with normal cells. These results indicated that the mouse $C F L 2$ gene may be involved in the regulation of $M y H C$ via the key signaling molecules of $C F L 2$-related signaling pathways.
\end{abstract}

Correspondence to: Professor Yuhong Su, College of Animal Science and Veterinary Medicine, Jinzhou Medical University, section 3, 40 Songpo Road, Linghe, Jinzhou, Liaoning 121001, P.R. China

E-mail: suyh652@sina.com

Key words: cofilin 2, gene expression, muscle, myosin heavy chain, mouse, RNA interference

\section{Introduction}

The cofilin 2 (CFL2) gene plays a key role in muscle development in mammals. CFL plays a crucial role in the regulation of actin by enhancing the turnover of actin filaments $(1,2)$. Mammalian $C F L$ occurs as non-muscle type $(C F L 1)$ or muscle-type (CFL2). In embryos, CFL1 is predominantly expressed in non-myoblast cells. The CFL2 protein appears in skeletal and cardiac myoblasts, particularly in the I bands and $\mathrm{Z}$ lines of skeletal myoblasts. During muscle development, $C F L 1$ expression decreases, while $C F L 2$ expression increases and eventually becomes predominant in mature mammalian skeletal myoblasts (3). The CFL2 transcript is spliced using either exon1a or exon $1 b$ to form the CFL2 $a$ and $C F L 2 b$ transcripts, respectively. The $C F L 2 a$ transcript is found in various tissues, while the $C F L 2 b$ transcript is mainly found in mature skeletal muscle. CFL binds and polymerizes filamentous F-actin and inhibits the polymerization of monomeric G-actin in a $\mathrm{pH}$-dependent manner, in part through interactions with tropomyosins $(4,5)$.

Four isoforms of myosin heavy chain $(\mathrm{MyHC})$ are expressed in skeletal muscle throughout the period of development, and are determinants of muscle development (6): I, slow oxidative; IIa, fast oxidative; IIb, fast glycolytic; and IIx/d, mixed (7). It was previously suggested that $M y H C$ composition affects meat quality in livestock (8). Meat characteristics, in particular edibility, may be strongly affected by muscle fiber types, which depend on $M y H C$ mRNA expression (8). Indeed, the expression of MyHC-I is associated with the $\mathrm{pH}$ value of the meat $24 \mathrm{~h}$ after death $\left(\mathrm{pH}_{24 \mathrm{~h}}\right)$ and drip loss (a characteristic of meat that represents its water-retaining capacity), while $M y H C$-II expression is correlated with juiciness, off-flavor, and tenderness of the meat (8). Our previous study demonstrated that $C F L 2 b$ overexpression regulated the fast muscle fiber trait by increasing the expression of MyHC-IIb and -IIx/d (9). However, the effects on $M y H C$ when CFL2 is disrupted have not been determined.

$M y H C$ and $C F L$ expression are associated with four cellular signaling pathways, including AMP-activated protein kinase (AMPK) $(10,11)$, calmodulin $(\mathrm{CaM})$, Rho, and mitogen-activated protein kinase (MAPK) (12-14). Five important proteins in these pathways, including extracellular 
signal-regulated kinase 2 (ERK2) (15), p38 MAPK (16), myocyte enhancer factor 2C (MEF2C) (17,18), cAMP-response element-binding protein (CBP) (16) and AMPK $\alpha 1$ (19), may affect the expression of $M y H C$ after inhibiting CFL2 expression.

To identify the involvement of $C F L 2$ in skeletal muscle and the period during which $C F L 2$ exerts its effects, the present study investigated the effects of $C F L 2$ on actin fibers by studying the $C F L 2$ and $M y H C$ genes in undifferentiated and differentiated $\mathrm{C} 2 \mathrm{C} 12$ cells transfected with the CFL2 siRNA. In addition, the protein expression of pathway-related genes, including ERK2, p38 MAPK, MEF2C, CBP and AMPK $\alpha 1$, was determined.

\section{Materials and methods}

Cell culture and transfection. Mouse $\mathrm{C} 2 \mathrm{C} 12$ myoblasts (GNM26) obtained from the Cell Bank of the Chinese Academy of Sciences (Shanghai, China) were grown in Dulbecco's modified Eagle's medium (DMEM) supplemented with $10 \%(\mathrm{v} / \mathrm{v})$ fetal calf serum (both from Invitrogen; Thermo Fisher Scientific, Carlsbad, CA, USA) at $37^{\circ} \mathrm{C}$ with $5 \% \mathrm{CO}_{2}$ in humidified chambers. Differentiation of $\mathrm{C} 2 \mathrm{C} 12$ cells was induced by replacing the medium with $2 \%$ horse serum for 6 days.

Cells in 6-well plates were transfected with CFL2 small interfering RNA (siRNA) using the liposome method (FuGene HD transfection reagent; Roche, Shanghai, China) when they reached $50 \%$ confluence, according to the manufacturer's instructions (9). The RNA interfering effects of siRNAs were confirmed by western blotting and reverse transcription-quantitative polymerase chain reaction (RT-qPCR). The undifferentiated cells were then screened with $500 \mu \mathrm{g} / \mathrm{ml}$ of G418 (Roche) to obtain single cell clones.

siRNA for CFL2 gene. Two siRNA pairs (CFL2-1 and CFL2-2; Table I) were selected for targeting the murine CFL2 gene (NM_007688) using a web-based siRNA design application (http://sirna.wi.mit.edu/home.php) (20). The selected siRNA pairs were then synthesized by Genechem (Shanghai, China). Undifferentiated cells were transfected with siRNA concentrations of 50, 100 and $150 \mathrm{nmol} / 1$ of CFL2-1, and 50 and $100 \mathrm{nmol} / \mathrm{l}$ of $C F L 2-2$. Cells transfected with scramble siRNA were used as controls. The effects of CFL2 siRNA were identified by RT-PCR and western blotting.

Experimental groups. Cells were divided into the following groups: Undifferentiated, $\mathrm{C} 2 \mathrm{C} 12$ cells transfected with scramble siRNA (UDN); undifferentiated, $\mathrm{C} 2 \mathrm{C} 12$ cells transiently transfected with CFL2 siRNA (UDT); differentiated, C2C12 cells transfected with scramble siRNA (DN); and differentiated, $\mathrm{C} 2 \mathrm{C} 12$ cells transiently transfected with $C F L 2$ siRNA (DT).

$R T$-PCR. RNA was extracted from $\mathrm{C} 2 \mathrm{C} 12$ cells using an RNeasy mini kit (Qiagen, Hilden, Germany), and first-strand cDNA was synthesized from purified total RNA with a reverse transcription kit (Takara, Dalian, China). RT-PCR was performed according to standard protocols using the primers indicated in Table II. The final volumes of each
Table I. siRNA sequences for the target sites in the CFL2 gene.

\begin{tabular}{llc}
\hline siRNA & \multicolumn{1}{c}{ Primer sequences (5'-3') } & Target site \\
\hline CFL2-1 & F: CUGAAAGUGCACCGUUAAAdTdT & $315-337$ \\
& R: UUUAACGGUGCACUUUCAGdTdT & \\
CFL2-2 & F: GCUCUAAAGAUGCCAUUAAdTdT & $354-376$ \\
& R: UUAAUGGCAUCUUUAGAGCdTdT & \\
Scramble & CTTGAAGGAAAGCCACTAT & -
\end{tabular}

CFL2, cofilin 2; F, forward primer; R, reverse primer.

Table II. RT-PCR primers for the target genes.

\begin{tabular}{llc}
\hline $\begin{array}{l}\text { Target } \\
\text { genes }\end{array}$ & \multicolumn{1}{c}{$\begin{array}{c}\text { Primer sequences } \\
\left(5^{\prime}-3^{\prime}\right)\end{array}$} & $\begin{array}{c}\text { PCR } \\
\text { product size }\end{array}$ \\
\hline CFL2 & F: ATCTTGGTGGGTGACATTGG & $322 \mathrm{bp}$ \\
& R: CAAGGGAAACTACAACACTGC & \\
GAPDH $H^{\text {a }}$ & F: GCAGTGGCAAAGTGGAGATT & $790 \mathrm{bp}$ \\
& R: TGAAGTCGCAGGAGACAACC & \\
GAPDH $H^{\mathrm{b}}$ & F: GCGAGACCCCACTAACATC & $171 \mathrm{bp}$ \\
& R: TTCACACCCATCACAAACA & \\
&
\end{tabular}

aPrimer of GAPDH used in Fig. 1A. 'Primer of GAPDH used in Fig.2A. RT-PCR, reverse transcription-polymerase chain reaction; CFL2, cofilin 2; GAPDH, glyceraldehyde 3-phosphate dehydrogenase; F, forward primer; $\mathrm{R}$, reverse primer.

reaction were $20 \mu \mathrm{l}$, including $10 \mathrm{pmol}$ primers, $2 \mathrm{mM} \mathrm{MgCl}$, $2.5 \mathrm{mM}$ dNTP, and $1 \mathrm{U}$ TaqDNA polymerase (Takara). The samples underwent PCR as follows: Denaturation for $5 \mathrm{~min}$ at $94^{\circ} \mathrm{C} ; 30$ cycles of $30 \mathrm{sec}$ at $94^{\circ} \mathrm{C}, 30 \mathrm{sec}$ at $56.7^{\circ} \mathrm{C}$, and $45 \mathrm{sec}$ at $72^{\circ} \mathrm{C}$; and extension for $10 \mathrm{~min}$ at $72^{\circ} \mathrm{C}$. Following amplification, $10 \mu \mathrm{l}$ PCR product was analyzed using $1 \%$ agarose gel electrophoresis and visualized using ethidium bromide and UV light.

$R T-q P C R$. RT-qPCR was performed to detect mRNA expression of MyHC-I, MyHC-IIa, MyHC-IIb, MyHC-IIx and glyceraldehyde 3-phosphate dehydrogenase $(G A P D H)$ in UDN, UDT, DN and DT. The cDNA template was prepared from mRNA directly harvested from CFL2-transfected cells at $1 \times 10^{6}$ cells/well. First-strand reverse transcription was performed using 100 ng total RNA with a reverse transcription kit (Takara); the RT-qPCR primers were also from Takara (Table III). SYBR-Green RT-qPCR assay for the target genes was performed in optical 96-well plates using the SYBR ${ }^{\circledR}$ Premix EX Taq ${ }^{\mathrm{TM}}$ II (DRR081A; Takara) and the 7500 Fast Real-Time PCR system (Applied Biosystems, Foster City, MA, USA), according to the manufacturer's instructions. Results were detected quantitatively in real-time by relative quantitation of two standard curves. The process consisted of 41 cycles, including 1 cycle of $10 \mathrm{sec}$ at $95^{\circ} \mathrm{C}$ and 40 cycles of $5 \mathrm{sec}$ at $95^{\circ} \mathrm{C}$ and $20 \mathrm{sec}$ at $60^{\circ} \mathrm{C}$. All experiments were performed three times, each time in triplicate. 
Table III. Oligonucleotide primers for RT-qPCR.

\begin{tabular}{|c|c|c|}
\hline Genes & $\begin{array}{l}\text { Primer sequences } \\
\qquad\left(5^{\prime}-3^{\prime}\right)\end{array}$ & $\begin{array}{l}\text { PCR } \\
\text { product } \\
\text { size }\end{array}$ \\
\hline MyHC-I & $\begin{array}{l}\text { F: ATGAGCTGGAGGCTGAGCA } \\
\text { R:TGCAGCCGCAGTAGGTTCTT }\end{array}$ & 124 bp \\
\hline МуНС-II & $\begin{array}{l}\text { F: ATTCTCAGGCTTCAGGATTTGGTG } \\
\text { R:CTTGCGGAACTTGGATAGATTTGTG }\end{array}$ & $114 \mathrm{bp}$ \\
\hline МyHC-IIb & $\begin{array}{l}\text { F: GAGTTCATTGACTTCGGGATGG } \\
\text { R:TGCTGCTCATACAGCTTGTTCTTG }\end{array}$ & 143 bp \\
\hline MyHC-IIx & $\begin{array}{l}\text { F: AAGGGTCTGCGCAAACATGA } \\
\text { R:TTGGCCAGGTTGACATTGGA }\end{array}$ & $173 \mathrm{bp}$ \\
\hline GAPDH & $\begin{array}{l}\text { F: GCGAGACCCCACTAACATC } \\
\text { R:TTCACACCCATCACAAACA }\end{array}$ & $171 \mathrm{bp}$ \\
\hline
\end{tabular}

RT-qPCR, reverse transcription-quantitative polymerase chain reaction; GAPDH, glyceraldehyde 3-phosphate dehydrogenase; MyHC, myosin heavy chain; F, forward primer; $R$, reverse primer.

Western blotting. Western blotting for CFL2, p38, ERK2, CBP, AMPK $\alpha 1$, MEF2C and GAPDH was performed in UDN and UDT. The cells were washed, harvested, lysed with a lysis buffer [20 mM Tris-Cl, pH 7.5, $150 \mathrm{mM} \mathrm{NaCl}, 1 \%$ sodium dodecyl sulfate (SDS), $1 \%$ Triton X-100, $10 \mu \mathrm{g} / \mathrm{ml}$ leupeptin, $1 \mathrm{mM}$ aprotinin and $1 \mathrm{mM}$ phenylmethanesulfonyl fluoride] on ice for $30 \mathrm{~min}$, and centrifuged at $14,000 \mathrm{x}$ g at $4^{\circ} \mathrm{C}$ for $15 \mathrm{~min}$. Proteins were resolved by SDS-polyacrylamide gel electrophoresis, transferred onto polyvinylidene difluoride membranes, blocked at room temperature for $1 \mathrm{~h}$ in $5 \%$ bovine serum albumin (BSA), and then incubated overnight at $4^{\circ} \mathrm{C}$ on a rotator with the primary antibodies: CFL2 (1:1,000; goat, SAB2500255; Sigma-Aldrich; Merck KGaA, St. Louis, MO, USA), p38 (1:1,000; mouse, ab31828), ERK2 (1:1,000; rabbit, ab32081), CBP (1:1,000; mouse, ab50702), AMPKa1 (1:1,000; mouse, ab80039) (all from Abcam, Cambridge, MA, USA), MEF2C (1:1,000; rabbit, SAB2103534; Sigma-Aldrich; Merck KGaA) and GAPDH (1:2,000; mouse, ab8245; Abcam). The membranes were washed four times with TBST and incubated for $1 \mathrm{~h}$ with an appropriate horseradish peroxidase (HRP)-conjugated secondary antibody $(1: 3,000)$. Immunoreactivity was visualized with an enhanced chemiluminescence detection reagent (ECL; Pierce, Rockford, IL, USA). All the experiments were performed three times, each time in triplicate.

CFL2 and F-actin analysis by fluorescence microscopy. CFL2 siRNA was transfected into cells. CFL2 and F-actin were labeled with fluorescein isothiocyanate (FITC) and tetramethylrhodamine (TRITC)-labeled phalloidin (Sigma-Aldrich; Merck KGaA) to differentiate between UDN and UDT. In terms of TRITC-labeled phalloidin methodology, UDN and UDT were grown on glass coverslips until they reached the logarithmic growth stage. Specimens were then washed three times in phosphate-buffered saline (PBS) and fixed with $4 \%$ paraformaldehyde at room temperature for $30 \mathrm{~min}$. After washing three times with PBS, the specimens were permea-
Table IV. Fluorescent staining of CFL2 and F-actin in C2C12 cells.

\begin{tabular}{lcc}
\hline & \multicolumn{2}{c}{ Fluorescent staining method } \\
\cline { 2 - 3 } $\begin{array}{l}\text { CFL2 expression } \\
\text { levels }\end{array}$ & CFL2 & F-actin \\
\hline Low & IgG antibody labeling & TRITC-labeled \\
& with FITC & phalloidin \\
Normal & IgG antibody labeling & TRITC-labeled \\
& with FITC & phalloidin \\
\hline
\end{tabular}

CFL2, cofilin 2; Ig, immunoglobulin; FITC, fluorescein isothiocyanate; TRITC, tetramethylrhodamine.

bilized with $0.2 \%$ Triton X-100 for $10 \mathrm{~min}$, washed three times with PBS, and blocked with $1 \%$ BSA for $30 \mathrm{~min}$. The coverslips were incubated for $10 \mathrm{~min}$ with diluted phalloidin (1:200, protected from light) and washed three times in PBS. The coverslips were mounted and observed with $90 \%$ glycerol in PBS. Notably, the FITC methodology is equivalent to the TRITC-labeled phalloidin approach, but additionally requires an overnight antibody incubation step prior to hybridization with diluted FITC (1:100, protected from light). UDN were used as controls. The cells were examined using a Zeiss epifluorescence microscope (Carl Zeiss AG, Oberkochen, Germany), as described in Table IV.

Statistical analyses. The results were analyzed using SPSS 17.0 software (IBM, Armonk, NY, USA). Data are presented as means \pm standard deviation. Experimental and control groups were compared using analysis of variance followed by Least Significant Difference post hoc analysis. P-values $<0.05$ were considered to indicate statistically significant differences.

\section{Results}

Knockdown of CFL2 by CFL2 siRNA. We first validated the RNA interference (RNAi) effects of $C F L 2$ siRNAs. RT-PCR amplification of $C F L 2$ and $G A P D H$ was analyzed (Fig. 1A). The results revealed that CFL2-1 siRNA at $50 \mathrm{nM}$ exerted the strongest inhibitory effect of all five experimental groups $(\mathrm{P}<0.05$; Fig. 1B), whereas, as expected, the scramble siRNA exerted no effect on CFL2 expression. The results of western blotting were consistent with the RT-PCR results (Fig. 1C and D). Therefore, the most effective siRNA sequence for $C F L 2$ was CFL2-1 siRNA at a concentration of $50 \mathrm{nM}$.

MyHC expression is downregulated in undifferentiated C2C12 cells treated with CFL2 RNAi. RNAi significantly inhibited CFL2 in undifferentiated cells $(\mathrm{P}<0.05)$ and in DT compared with DN ( $\mathrm{P}<0.05$; Fig. $2 \mathrm{~A}$ and $\mathrm{B})$. Therefore, regardless of cellular differentiation, RNAi significantly inhibited CFL2 mRNA expression in C2C12 cells. Western blot analyses were also consistent with the RT-PCR results (P<0.05; Fig. 2C and D).

RT-qPCR amplification was used to determine the expression of $\mathrm{MyHC}$ genes in differentiated and undifferentiated 


\section{A}

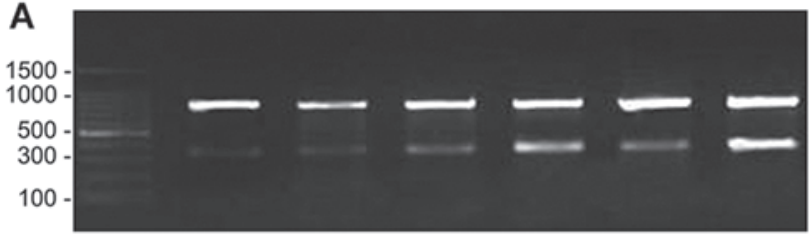

M

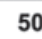

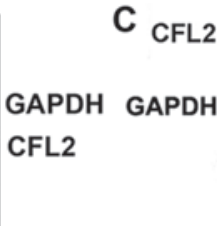

$\mathrm{C}_{\mathrm{CFL2}}$

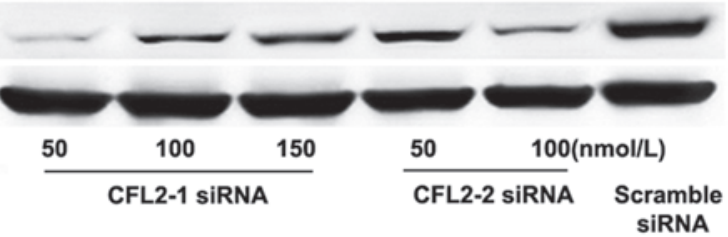

B
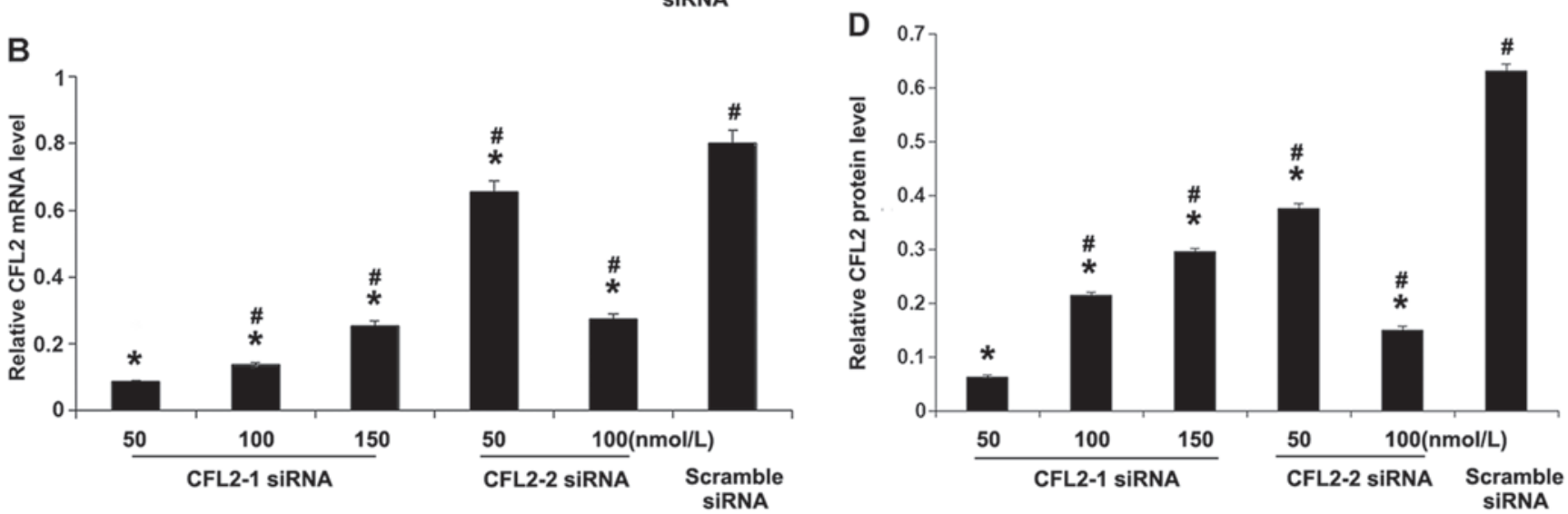

Figure 1. Cofilin 2 (CFL2) mRNA and protein expression in C2C12 cells transfected with CFL2 siRNA. (A) Representative image of RT-PCR. (B) Statistical data of (A). (C) Representative image of western blotting. (D) Statistical data of (C). The histogram shows the results as mean \pm standard deviation of three experiments performed in triplicate. Expression was normalized to glyceraldehyde 3-phosphate dehydrogenase (GAPDH). M, 100 bp standard marker. ${ }^{*}<0.05$ vs. scramble siRNA group; ${ }^{\#} \mathrm{P}<0.05$ vs. CLF2-1 siRNA $50 \mathrm{nmol} / 1$. siRNA, small interfering RNA; RT-PCR, reverse transcription-polymerase chain reaction.
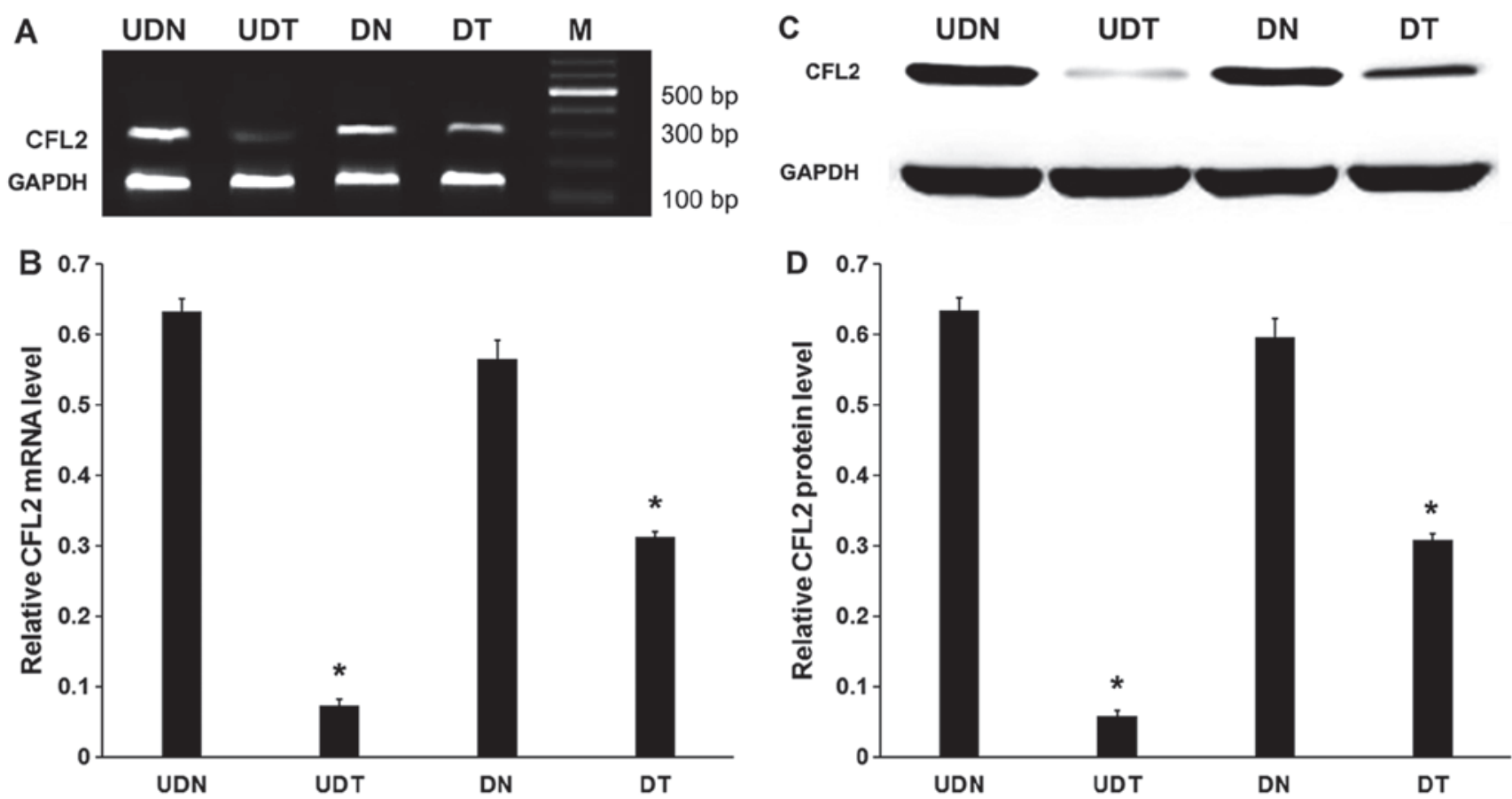

Figure 2. Cofilin 2 (CFL2) mRNA and protein expression after RNAi in undifferentiated and differentiated C2C12 cells. (A) Representative image of RT-PCR of CFL2 and glyceraldehyde 3-phosphate dehydrogenase (GAPDH). M, 100 bp standard marker. (B) Statistical data. GAPDH was used as an internal control (C) Representative image of western blotting of CFL2 and GAPDH. (D) Statistical data. GAPDH was used as an internal control. All experiments were performed three times, each time in triplicate. ${ }^{\mathrm{P}}<0.05$ UDT vs. UDN and DT vs. DN. UDN, undifferentiated C2C12 cells transfected with scramble siRNA; UDT, undifferentiated $\mathrm{C} 2 \mathrm{C} 12$ cells transiently transfected with CFL2 siRNA; DN, differentiated C2C12 cells transfected with scramble siRNA; DT, differentiated C2C12 cells transiently transfected with CFL2 siRNA.

C2C12 cells following CFL2 siRNA transfection. The $M y H C /$ $G A P D H$ expression in undifferentiated and differentiated cells is shown in Fig. 3. MyHC-I, MyHC-IIa, MyHC-IIb and MyHC-IIx gene expressions were significantly decreased in UDT $(\mathrm{P}<0.05)$. 


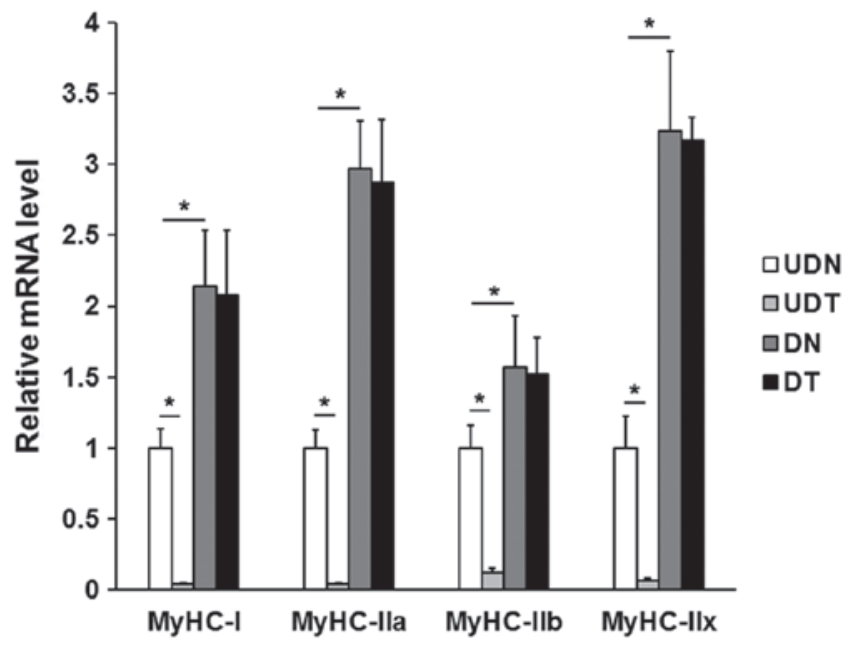

Figure 3. Myosin heavy chain $(M y H C)$ mRNA expression with cofilin 2 (CFL2) RNAi in differentiated and undifferentiated $\mathrm{C} 2 \mathrm{C} 12$ cells, using RT-qPCR. Glyceraldehyde 3-phosphate dehydrogenase (GAPDH) was used as an internal control. The level of mRNA in the UDN group was set as 1 and the other groups were normalized to UDN. All experiments were performed three times, each time in triplicate. ${ }^{* *} \mathrm{P}<0.01$. RT-qPCR, reverse transcription-quantitative polymerase chain reaction; UDN, undifferentiated $\mathrm{C} 2 \mathrm{C} 12$ cells transfected with scramble siRNA; UDT, undifferentiated $\mathrm{C} 2 \mathrm{C} 12$ cells transiently transfected with CFL2 siRNA; DN, differentiated C2C12 cells transfected with scramble siRNA; DT, differentiated C2C12 cells transiently transfected with CFL2 siRNA.

However, in DT, RNAi had almost no effect on $M y H C$ expression, suggesting that $\mathrm{MyHC}$ expression is generally proportional to that of CFL2 prior to differentiation of cells into muscle fibers. These results suggest that $M y H C$ mRNA expression was elevated after differentiation $(\mathrm{P}<0.05)$, and that $M y H C$ genes were not significantly affected by downregulation of CFL2 only in undifferentiated cells. With this in mind, subsequent experiments were only performed in the UDT and UDN groups.

Muscle fiber signaling pathway-related factors are altered by CFL2 RNAi in undifferentiated C2C12 cells. The expression of key signaling molecules in the AMPK, CaM, Rho and MAPK pathways (including p38 MAPK, ERK2, CBP, AMPK $\alpha 1$ and MEF2C) was measured by western blotting. The expressions of p38 MAPK, CBP, AMPK $\alpha 1$ and MEF2C proteins were significantly decreased in UDT $(\mathrm{P}<0.05)$. By contrast, ERK2 protein expression was significantly increased compared with UDN (P<0.05; Fig. 4).

CFL2 alters $F$-actin formulation in C2C12 cells. In UDN, CFL2 (green fluorescence) was diffusely distributed in the cytoplasm and nucleus of the cells (Fig. 5A). UDT exhibited a similar diffuse CFL2 distribution pattern (Fig. 5B).

F-actin structures were not significantly different in UDT compared to UDN with CFL2 expression. The F-actin bundles, however, exhibited a tendency to form amorphous diffuse patterns (Fig. 5C and D).

\section{Discussion}

The aim of the present study was to demonstrate the effects of the mouse myosin-binding protein CFL2 on the expression of $M y H C$, which may play a pivotal role in the cytoskeleton in undifferentiated $\mathrm{C} 2 \mathrm{C} 12$ cells. The functions of CFL2 in undifferentiated and differentiated $\mathrm{C} 2 \mathrm{C} 12$ cells were investigated and the results suggested that, in undifferentiated cells, the expression of $M y H C$ genes decreased significantly after CFL2 RNAi; however, there was no obvious change in differentiated cells.

Effects of CFL2 on muscle fiber types. Four $M y H C$ isoforms (I, IIa, IIx and IIb) are expressed in adult skeletal muscles (6). MyHCs are the primary molecular markers for distinguishing muscle fiber types and studying their characteristics. When CFL2 gene expression in $\mathrm{C} 2 \mathrm{C} 12$ myoblasts is suppressed, the expression of MyHC-I, MyHC-IIa, MyHC-IIb and MyHC-IIx is significantly downregulated.

In addition, 6 days after $\mathrm{C} 2 \mathrm{C} 12$ differentiation was induced using $2 \%$ horse serum, the CFL2 mRNA and protein expressions in DN were not significantly different from those in undifferentiated cells. The expression of $M y H C-I, M y H C$-IIa, $M y H C$ - IIb and MyHC-IIx increased, indicating that $M y H C$ is associated with myoblast differentiation. However, RNAi no longer affected the types of $M y H C$. This may indicate that interactions between CFL2 and MyHCs only occur in undifferentiated cells.

Molecular mechanisms of MyHC in C2C12 cells and CFL2 involvement. Within the four key cellular signaling pathways involved in muscle fiber regulation, there are five important signaling factors: p38 MAPK, ERK2, CBP, MEF2C and AMPK $\alpha 1$. The fast muscle fibers $(M y H C$-IIb/IIx) are preferentially affected by MAPK signaling. The dual-specific mitogen-activated protein kinase kinase 3 (MKK3) and the constitutively active MKK6 mutant upstream of p38 MAPK are involved in the maintenance of the fast muscle fiber phenotype (21); they may also be involved in the regulation of MyHC-IIx promoter activity in myotubes $(12,22)$. The ERK pathway is also a major pathway that affects fast fibers, as demonstrated by increased $M y H C$ - IIx and $M y H C$ - IIb transcripts and decreased $M y H C$ - $I$ expression following ablation of the ERK1/2 pathway in cultured rat fetal myocytes (23). This mechanism is also consistent with the downregulation of CFL2 genes as a means to decrease p38 MAPK, $M y H C$ - IIb and $M y H C$-IIx expression and to increase ERK2 expression.

It was previously reported that ERK $1 / 2$ activity is more than 2-fold higher in fast muscle fibers compared with that in slow muscle fibers (15), suggesting that the ERK1/2 pathway may play a key role in maintaining the fast fiber phenotype. When p38 MAPK activity is inhibited, the promoter activities of fast-type $M y H C$-IIb and $M y H C$-IIx are downregulated. Moreover, p38 $\alpha / \beta$ MAPK is known to mediate $M y H C-I I b$ and $M y H C-I I x$ expression via CBP and the $M E F 2 C / D$ heterodimer (16). When combined with other transcriptional factors (17), $M E F 2 C$ may affect $M y H C$ isoform expression in mouse skeletal muscle (18). These prior findings are highly consistent with the results of the present study, in which $M E F 2 C$ and $C B P$ expression was decreased by CFL2 RNAi. Furthermore, a decrease in $M E F 2 C$ expression has been associated with a decrease in $M y H C$-I muscle fibers (24). Expression of the $M E F 2 C$ subunits may also be involved in activation of the p38 MAPK pathway. Thus, $M E F 2 C$ and p38 synergistically regulate and promote type I muscle fibers. 

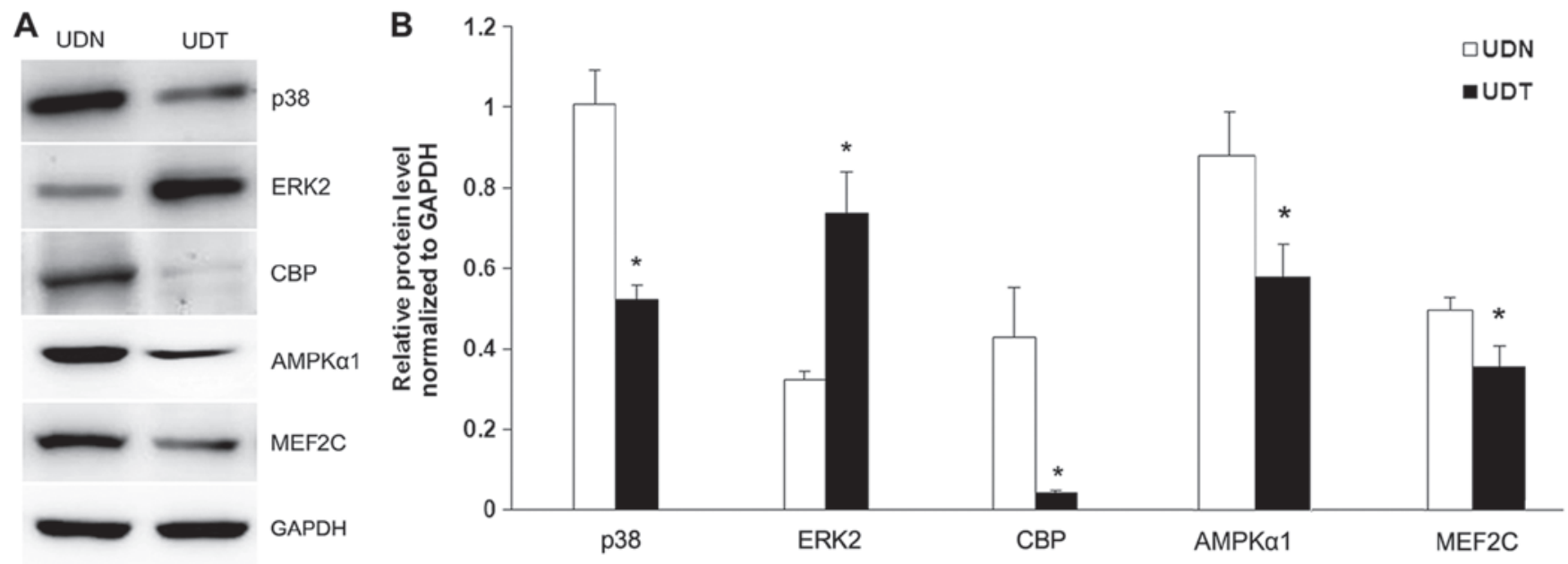

Figure 4. p38, ERK2, CBP, AMPK $\alpha 1$ and MEF2C protein expression in UDN and UDT. (A) Representative image of western blotting of p38, ERK2, CBP, AMPK $\alpha 1$ and MEF2C protein expression in UDN and UDT. (B) Statistical data. Glyceraldehyde 3-phosphate dehydrogenase (GAPDH) was used as an internal control. All experiments were performed three times, each time in triplicate. "P $<0.05$ vs. UDN. UDN, undifferentiated $\mathrm{C} 2 \mathrm{C} 12$ cells transfected with scramble siRNA; UDT, undifferentiated C2C12 cells transiently transfected with CFL2 siRNA; ERK2, extracellular signal-regulated kinase 2; CBP, cAMP-response element-binding protein; AMPK, AMP-activated protein kinase; MEF2C, myocyte enhancer factor 2C.
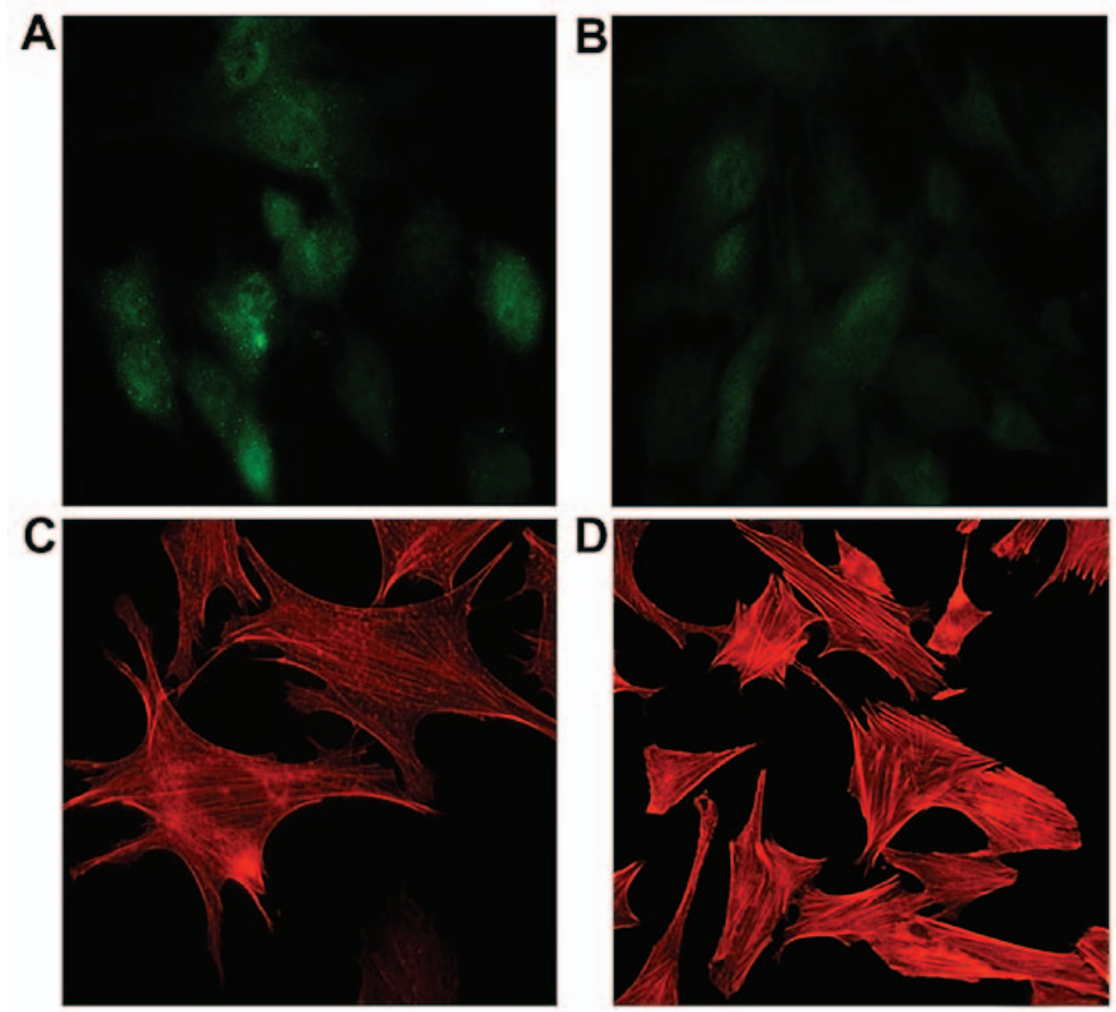

Figure 5. Cofilin 2 (CFL2) and F-actin localization in C2C12 cells. (A and B) CFL2 expression and distribution pattern in UDN and UDT (magnification, $\mathrm{x} 200$ ). (C and D) F-actin expression and distribution pattern in UDN and UDT (magnification, $\mathrm{x} 200$ ). UDN, undifferentiated C2C12 cells transfected with scramble siRNA; UDT, undifferentiated C2C12 cells transiently transfected with CFL2 siRNA.

Previously, the authors observed that skeletal muscle in wild-type mice commonly undergoes an AMPK-mediated shift from $M y H C$-IIb to $M y H C$-II $a$ and $M y H C$-IIIx during exercise training (10). These prior results indicated that $A M P K \alpha 1$ and $A M P K \alpha 2$ may also alter skeletal muscle composition. This is consistent with the present results, which demonstrated downregulation of AMPKal, MyHC-IIa, MyHC-IIb and MyHC-IIx following CFL2 RNAi.
Notably, $\mathrm{MyHC}$ gene expression was altered in UDT due to RNAi, resulting in downregulation of $\mathrm{MyHC}-\mathrm{I}, \mathrm{MyHC}-\mathrm{IIa}$, $M y H C$-IIb and MyHC-IIx expression. Glycolytic fibers (MyHC-IIb) are the most common among these four muscle fiber types. According to the $M y H C$ conversion rules (25-27), MyHC-I primarily transforms into MyHC-IIa. Additional studies are required to confirm the findings of the present study, in part owing to the complexity of $\mathrm{MyHC}$ conversion due 
to overlapping signaling pathways. Additionally, the $M y H C$ isoforms that play a key role in the regulation of fast fibers may play a less important role in the regulation of slow fibers under certain physiological conditions. Although $\mathrm{MyHC}-\mathrm{I}$ expression was also found to be decreased in the present study, other isoforms may be able to convert MyHCs. Future studies are required to elucidate these isoforms and their roles in the mechanism of $\mathrm{MyHC}$ conversion.

In conclusion, the findings of the present study indicate that mouse $C F L 2$ may regulate $M y H C$. In addition, the expression of four $M y H C$ isoforms in undifferentiated cells with $C F L 2$ RNAi was found to be significantly decreased compared with that in differentiated cells. However, further investigations on the exact association of $C F L 2$ with signaling pathway-related factors are required to fully elucidate the role of $C F L 2$ in the regulation of $\mathrm{MyHC}$.

\section{Acknowledgements}

The present study was supported by the National Natural Science Foundations of China (grant no. 31272415/C170102), the Natural Science Foundations of Liaoning Province (grant no. 2015020765) and the Training Programs of Innovation and Entrepreneurship for Undergraduates of Liaoning Province (grant no. 201610160051).

\section{References}

1. Chhabra D and dos Remedios CG: Cofilin, actin and their complex observed in vivo using fluorescence resonance energy transfer. Biophys J 89: 1902-1908, 2005.

2. Papalouka V, Arvanitis DA, Vafiadaki E, Mavroidis M, Papadodima SA, Spiliopoulou CA, Kremastinos DT, Kranias EG and Sanoudou D: Muscle LIM protein interacts with cofilin 2 and regulates $\mathrm{F}$-actin dynamics in cardiac and skeletal muscle. Mol Cell Biol 29: 6046-6058, 2009.

3. Mohri K, Takano-Ohmuro H, Nakashima H, Hayakawa K, Endo T, Hanaoka K and Obinata T: Expression of cofilin isoforms during development of mouse striated muscles. J Muscle Res Cell Motil 21: 49-57, 2000.

4. Gillett GT, Fox MF, Rowe PS, Casimir CM and Povey S: Mapping of human non-muscle type cofilin (CFL1) to chromosome 11q13 and muscle-type cofilin (CFL2) to chromosome 14. Ann Hum Genet 60: 201-211, 1996.

5. Ono S and Ono K: Tropomyosin inhibits ADF/cofilin-dependent actin filament dynamics. J Cell Biol 156: 1065-1076, 2002.

6. Asaduzzaman M, Kinoshita S, Siddique BS, Asakawa S and Watabe S: Multiple cis-elements in the 5'-flanking region of embryonic/larval fast-type of the myosin heavy chain gene of torafugu, MYH(M743-2), function in the transcriptional regulation of its expression. Gene 489: 41-54, 2011.

7. Solomon MB, West RL and Carpenter JW: Fiber types in the longissimus muscle from water buffalo and selected domestic beef breeds. Meat Sci 13: 129-135, 1985.

8. Kang YK, Choi YM, Lee SH, Choe JH, Hong KC and Kim BC: Effects of myosin heavy chain isoforms on meat quality, fatty acid composition, and sensory evaluation in Berkshire pigs. Meat Sci 89: 384-389, 2011.

9. Zhao W, Su YH, Su RJ, Ba CF, Zeng RX and Song HJ: The full length cloning of a novel porcine gene CFL2b and its influence on the MyHC expression. Mol Biol Rep 36: 2191-2199, 2009.
10. Röckl KS, Hirshman MF, Brandauer J, Fujii N, Witters LA and Goodyear LJ: Skeletal muscle adaptation to exercise training: AMP-activated protein kinase mediates muscle fiber type shift. Diabetes 56: 2062-2069, 2007.

11. Miranda L, Carpentier S, Platek A, Hussain N, Gueuning MA, Vertommen D, Ozkan Y, Sid B, Hue L, Courtoy PJ, et al: AMP-activated protein kinase induces actin cytoskeleton reorganization in epithelial cells. Biochem Biophys Res Commun 396: 656-661, 2010.

12. Long YC, Widegren U and Zierath JR: Exercise-induced mitogen-activated protein kinase signalling in skeletal muscle. Proc Nutr Soc 63: 227-232, 2004.

13. Madak-Erdogan Z, Ventrella R, Petry L and Katzenellenbogen BS: Novel roles for ERK5 and cofilin as critical mediators linking ER $\alpha$-driven transcription, actin reorganization, and invasiveness in breast cancer. Mol Cancer Res 12: 714-727, 2014.

14. Won KJ, Park SH, Park T, Lee CK, Lee HM, Choi WS, Kim SJ, Park PJ, Jang HK, Kim SH, et al: Cofilin phosphorylation mediates proliferation in response to platelet-derived growth factor-BB in rat aortic smooth muscle cells. J Pharmacol Sci 108: 372-379, 2008.

15. Yang SH, Sharrocks AD and Whitmarsh AJ: MAP kinase signalling cascades and transcriptional regulation. Gene 513: 1-13, 2013.

16. Meissner JD, Chang KC, Kubis HP, Nebreda AR, Gros G and Scheibe RJ: The p38alpha/beta mitogen-activated protein kinases mediate recruitment of CREB-binding protein to preserve fast myosin heavy chain IId/x gene activity in myotubes. J Biol Chem 282: 7265-7275, 2007.

17. Al Madhoun AS, Mehta V, Li G, Figeys D, Wiper-Bergeron N and Skerjanc IS: Skeletal myosin light chain kinase regulates skeletal myogenesis by phosphorylation of MEF2C. EMBO J 30: 2477-2489, 2011

18. Lu J, McKinsey TA, Nicol RL and Olson EN: Signal-dependent activation of the MEF2 transcription factor by dissociation from histone deacetylases. Proc Natl Acad Sci USA 97: 4070-4075, 2000.

19. Wright DC, Hucker KA, Holloszy JO and Han DH: $\mathrm{Ca}^{2+}$ and AMPK both mediate stimulation of glucose transport by muscle contractions. Diabetes 53: 330-335, 2004.

20. Reynolds A, Leake D, Boese Q, Scaringe S, Marshall WS and Khvorova A: Rational siRNA design for RNA interference. Nat Biotechnol 22: 326-330, 2004.

21. Delling U, Tureckova J, Lim HW, De Windt LJ, Rotwein P and Molkentin JD: A calcineurin-NFATc3-dependent pathway regulates skeletal muscle differentiation and slow myosin heavychain expression. Mol Cell Biol 20: 6600-6611, 2000.

22. Kramer HF and Goodyear LJ: Exercise, MAPK, and NF-kappaB signaling in skeletal muscle. J Appl Physiol (1985) 103: 388-395, 2007.

23. Shi H, Scheffler JM, Pleitner JM, Zeng C, Park S, Hannon KM, Grant AL and Gerrard DE: Modulation of skeletal muscle fiber type by mitogen-activated protein kinase signaling. FASEB J 22: 2990-3000, 2008.

24. Bassel-Duby R and Olson EN: Signaling pathways in skeletal muscle remodeling. Annu Rev Biochem 75: 19-37, 2006.

25. Weiss A, McDonough D, Wertman B, Acakpo-Satchivi L, Montgomery K, Kucherlapati R, Leinwand L and Krauter K: Organization of human and mouse skeletal myosin heavy chain gene clusters is highly conserved. Proc Natl Acad Sci USA 96: 2958-2963, 1999.

26. Whitmer JD, Koslovsky JS, Bähler $M$ and Mercer JA: Chromosomal location of three unconventional myosin heavy chain genes in the mouse. Genomics 38: 235-237, 1996.

27. Knotts S, Rindt H, Neumann J and Robbins J: In vivo regulation of the mouse beta myosin heavy chain gene. J Biol Chem 269: 31275-31282, 1994. 